\title{
Maintenance of intestinal homeostasis by mucosal barriers
}

Ryu Okumura ${ }^{1,2,3}$ and Kiyoshi Takeda ${ }^{1,2,3^{*}}$

\begin{abstract}
Background: The intestine is inhabited by a tremendous number of microorganisms, which provide many benefits to nutrition, metabolism and immunity. Mucosal barriers by intestinal epithelial cells make it possible to maintain the symbiotic relationship between the gut microbiota and the host by separating them. Recent evidence indicates that mucosal barrier dysfunction contributes to the development of inflammatory bowel disease (IBD). In this review, we focus on the mechanisms by which mucosal barriers maintain gut homeostasis.
\end{abstract}

Main text: Gut mucosal barriers are classified into chemical and physical barriers. Chemical barriers, including antimicrobial peptides (AMPs), are chemical agents that attack invading microorganisms, and physical barriers, including the mucus layer and the cell junction, are walls that physically repel invading microorganisms. These barriers, which are ingeniously modulated by gut microbiota and host immune cells, spatially segregate gut microbiota and the host immunity to avoid unnecessary immune responses to gut commensal microbes. Therefore, mucosal barrier dysfunction allows gut bacteria to invade gut mucosa, inducing excessive immune responses of the host immune cells, which result in intestinal inflammation.

Conclusion: Gut mucosal barriers constructed by intestinal epithelial cells maintain gut homeostasis by segregating gut microbiota and host immune cells. Impaired mucosal barrier function contributes to the development of IBD. However, the mechanism by which the mucosal barrier is regulated by gut microbiota remains unclear. Thus, it should be further elucidated in the future to develop a novel therapeutic approach to IBD by targeting the mucosal barrier.

Keywords: Mucosal barrier, Gut microbiota, Intestinal epithelial cells, Inflammatory bowel disease

\section{Background}

The mammalian intestine is a special place for microorganisms, where a high abundance of nutrients derived from foods are present and an aerobic condition is maintained. Therefore, tremendous numbers of microorganisms mainly composed of aerobic bacteria grow and inhabit the intestine. The intestinal microorganisms including bacteria, fungi and viruses form an ecological community termed the gut microbiota, which does not only reside in the gut but also provide many benefits to nutrition, metabolism and immunity. Short-chain fatty acid (SCFA), which is a gut microbial metabolite produced from dietary fibers, is used as an energy source of the host. In addition, SCFA

\footnotetext{
* Correspondence: ktakeda@ongene.med.osaka-u.ac.jp

'Department of Microbiology and Immunology, Graduate School of Medicine, Osaka University, Osaka 565-0871, Japan

${ }^{2}$ WPI Immunology Frontier Research Center, Osaka University, Osaka 565-0871, Japan

Full list of author information is available at the end of the article
}

contributes to the modulation of mucosal immunity by enhancing mucus production and promoting regulatory $\mathrm{T}$ cell $\left(\mathrm{T}_{\text {reg }}\right)$ development [1-3]. Moreover, gut bacteria synthesize several kinds of vitamins including vitamin B and vitamin $\mathrm{K}$, which are critical for sugar and fat metabolism and maintenance of hemostatic function. Thus, gut microbiota forms a win-win relationship with the host.

However, mammalian immune cells such as macrophages and neutrophils are programmed to attack invading extraneous organisms. Gut microbes are no exception and can be targeted by host immune cells. Accordingly, there is a barrier system-mucosal barrier-for separating gut microbiota and the host immunity to avoid an unfavorable interaction between the two. Mucosal barrier impairment allows gut microbes to easily enter the mucosa, which induce intestinal inflammation as a consequence of the host's excessive immune responses to gut microbes.

Inflammatory bowel diseases (IBD) such as Crohn's disease (CD) and ulcerative colitis (UC) involve choric 
intestinal inflammation in humans. Recent evidence based on the combination of the human genome-wide association study (GWAS) and genetically modified mouse studies have revealed that intestinal barrier dysfunction is one cause of IBD [4]. In addition, reduced production of mucosal barrier components such as mucus and antimicrobial peptides is observed in the intestine of some IBD patients. These findings indicate that the mucosal barrier is indispensable for maintaining the gut environment and preventing intestinal inflammation.

In this review, we discuss the mechanisms of the gut mucosal barrier constructed by IECs and the regulation of intestinal inflammation by the mucosal barrier.

\section{Mucosal barriers formed by intestinal epithelial cells}

IECs at the surface of the gut mucosa absorb nutrients and water from ingested foods. They also play important roles in generating various types of barriers to protect mucosa from commensal microbes and invading pathogenic microorganisms (Fig. 1). These barriers have two subtypes, chemical and physical barriers.

\section{Chemical barrier}

Chemical barriers consist of antimicrobial peptides (AMPs), the regenerating islet-derived 3 (Reg3) family of proteins, lysozyme and secretory phospholipase A2. All of these are mainly involved in the segregation of gut bacteria and IECs in the small intestine $[5,6]$. Paneth cells play a crucial role in the mucosal barrier of the small intestine by producing a large number of antimicrobials [7].

AMPs are basic amino acid-rich cationic small proteins, which are evolutionally conserved in a wide range of organisms. They include the defensin family of proteins and cathelicidins, both of which bind to the negatively charged microbial cell membrane and induce disruption of membrane integrity by forming a pore-like structure [8]. Defensin family proteins are classified into $\alpha$-, $\beta$ - and $\theta$-defensins, among which $\alpha$ defensin (also referred to as cryptdins in mice) is most highly expressed in Paneth cells and mainly protects against infection by Gram-positive and Gram-negative bacteria. Pro-cryptdin is converted into mature-cryptdin by matrix metalloproteinase-7 (MMP-7) in mice. Therefore, MMP-7-deficient mice lack mature-cryptdin, resulting in high susceptibility to Salmonella typhimurium infection [9]. Moreover, mature $\alpha$-defensin deficiency is associated with alteration of the gut microbiota: a decrease of Bacteroidetes and an increase in Firmicutes [10]. These results demonstrate that AMPs largely contribute to the homeostatic state of the gut environment by regulating pathogenic bacteria [11].

The Reg3 family proteins are C-type lectins, which exert an antibacterial effect on Gram-positive bacteria by binding to the bacterial membrane and forming a hexameric membrane-permeabilizing oligomeric pore [12]. In mice lacking Reg3y, increased bacterial colonization on the epithelial surface of the small intestine was observed, indicating that Reg3y is indispensable to the spatial separation of the intestinal bacteria and intestinal epithelia of the small intestine $[6,12,13]$.

\section{Physical barriers}

Chemical barriers are major players in the segregation of gut microbiota and the small intestinal epithelia. However,
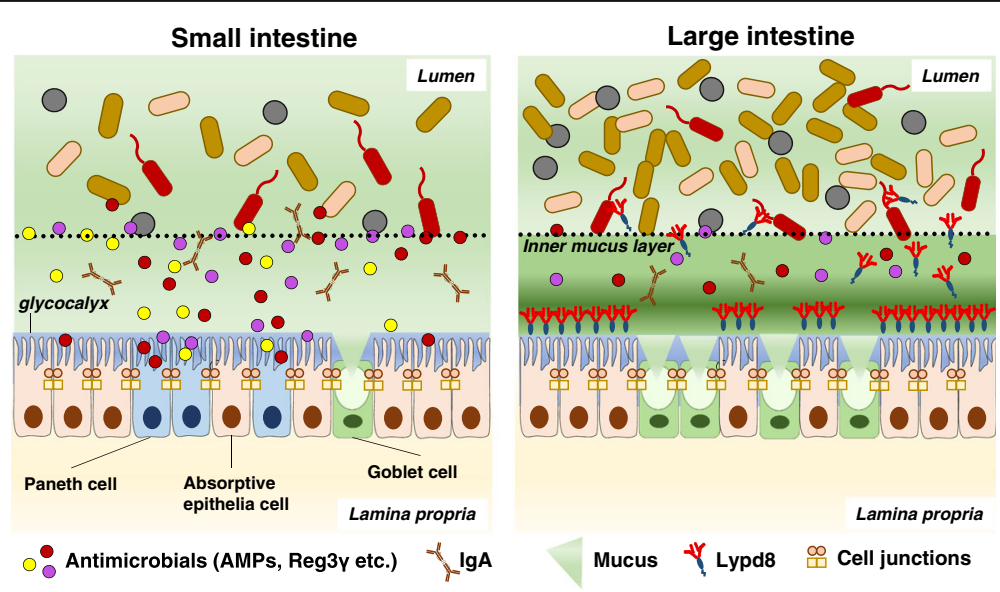

Fig. 1 Mucosal barriers in the gut. Chemical barriers including AMPs and Reg3y secreted by Paneth cells mainly contribute to the separation between intestinal bacteria and IECS in the small intestine. By contrast, in the large intestine where a tremendous number of bacteria exist, intestinal bacteria and IECs are largely segregated by physical barriers such as the inner mucus layer composed of polymerized MUC2 mucin. Lypd8, a highly glycosylated GPI-anchored protein expressed on IECs, inhibits the bacterial invasion of the inner mucus layer by binding to intestinal bacteria, especially flagellated bacteria. AMP: antimicrobial peptide 
in the large intestine, where there is nothing resembling Paneth cells that secrete antimicrobials, physical barriers mainly contribute to spatial segregation of gut microbiota and intestinal epithelia. Physical barriers consist of the mucus layer covering the intestinal mucosa, the glycocalyx on the microvilli of absorptive IECs, and the cell junctions firmly linking IECs. These barriers physically inhibit the microbial invasion of the mucosa.

Mucus is a viscous fluid secreted by goblet cells. It is enriched in mucin glycoproteins that form large net-like polymers [14]. In the large intestine, where tremendous numbers of intestinal bacteria exist compared with the small intestine, the number of goblet cells is much higher and the large intestinal epithelia are covered by a thick twolayered mucus layer: the outer loose and the inner firm mucus layer [15]. These two mucus layers are constructed of goblet cell-secreted Mucin2 (MUC2) protein, which is a highly $O$-glycosylated protein, forming large net-like structures. The inner mucus layer is stratified and anchored to the intestinal epithelia, which does not allow gut bacteria to easily penetrate into the inner mucus layer and thereby keeps the inner mucus layer free of bacteria [15]. The inner mucus layer is converted into the outer mucus layer by the proteolytic processing of polymerized MUC2 by the host or gut bacteria. The outer mucus layer is inhabited by numerous bacteria, some of which use polysaccharides of MUC2 as an energy source; therefore, the absence of dietary fiber, a major energy source of intestinal bacteria, leads to the expansion of mucin-degrading species, resulting in the increase of inner mucus degradation [16].

Regarding the mechanism by which the inner mucus layer is free of gut bacteria, various antimicrobial molecules such as immunoglobulin A (IgA) and the defensin family of proteins transported or produced by IECs may be involved in protecting against bacterial invasion of the inner mucus layer [17]. Although higher numbers of bacteria exist in the large intestine, the expression level of antimicrobial molecules in the large intestine is not higher than that in the small intestine, indicating that there is another mechanism to inhibit gut microbial invasion of the large intestinal epithelia without killing bacteria.

Ly6/Plaur domain containing 8 (Lypd8) is a highly glycosylated GPI-anchored protein highly and selectively expressed on the mucosal surface of the large intestine. A recent study demonstrated that many intestinal bacteria, including Escherichia spp. and Proteus spp., invaded the inner mucus layer in Lypd8-deficient mice [18]. In addition, it was revealed that Lypd8 inhibited bacterial motility of flagellated bacteria such as Escherichia coli and Proteus mirabilis through binding to their flagella, thereby inhibiting their bacterial invasion of the colonic epithelia. These results indicate that Lypd8 contributes to the segregation of intestinal bacteria and the large intestinal epithelia [18].
As mentioned above, Muc2 and Lypd8 are highly glycosylated. Glycans of the physical barrier-related proteins are critical for maintaining their barrier function. In mice lacking the $\mathrm{O}$-glycan core structure of the MUC2 protein, bacterial invasion of the colonic mucosa was observed [19]. With removal of $N$-glycans from Lypd8, the inhibitory effect of Lypd8 against bacterial attachment on Caco-2 cells was severely reduced [18]. Furthermore, mice devoid of Fut2, which mediates the transfer of fucoses to the terminal galactose on glycans in cell-surface glycoproteins, are highly susceptible to pathogenic bacteria infection [20,21]. The glycocalyx, a meshwork of carbohydrate moieties of glycolipids or glycoproteins including transmembrane mucins, blocks bacterial invasion into the intestinal tissue as a second wall followed by the mucus layer. These findings indicate that glycans of barrier-related proteins generated by IECs are vital for physical barrier function.

For intestinal bacteria passing through the mucus layer and glycocalyx by evading various kinds of antimicrobial molecules from the host, cell junctions, including the tight and adhesion junctions linking epithelial cells, are the final wall to physically hamper the invasion into the intestinal tissue through the paracellular pathway. Hence, the perturbed gut integrity and permeability caused by disruption of the cell junction of IECs leads to microbial translocation, and the consequent leakage of bacteria or their metabolites into the gut tissue can induce a chronic or acute inflammatory response in the intestine $[22,23]$.

\section{Regulation of mucosal barrier function by gut microbiota and immune cells}

Mucosal barrier function is regulated by various signals from gut microbiota and host immune cells. IECs express a variety of pattern recognition receptors, including Toll-like receptors (TLRs) and nucleotide-binding oligomerization domain-containing proteins (NODs) to directly sense bacterial components. The production of antimicrobial molecules by IECs is controlled by TLR4/MyD88 signaling and NOD2 signaling driven by gut microorganisms $[5,6,24]$. In mice deficient in NOD2 sensing muramyl dipeptides, which are conserved structures in bacterial peptidoglycans, the expression of defensins is substantially reduced, resulting in high susceptibility to Listeria monocytogenes infection [24]. Moreover, mice lacking MyD88 in IECs show the decreased production of AMPs, Reg3y and mucus by IECs, and eventually they become highly susceptible to experimental colitis and enteric bacterial infection [25, 26]. In addition, recent studies demonstrated that NODlike receptor family pyrin domain containing 6 (NLRP6), a member of the NOD-like receptor family of pattern recognition receptors, is necessary for mucus granule exocytosis from goblet cells [27]. 
Metabolites from gut bacteria also directly enhance the mucosal barrier function of IECs. Mucus secretion from goblet cells is upregulated by butyrate, one of the SCFAs provided by gut bacteria [28]. Recent evidence revealed that the expression of cell junction-associated molecules such as occludins and claudins in IECs is enhanced by indole, a metabolite of dietary tryptophan from commensal bacteria possessing tryptophanase, via Pregnane X receptor (PXR) stimulation [29, 30].

The mucosal barrier function of IECs is also enhanced by cytokines from immune cells activated by gut commensal bacteria or pathogenic bacteria. Segmented filamentous bacteria (SFB) is a type of commensal bacteria found in the mouse or rat intestine. The attachment of SFB to IECs strongly promotes Th17 cell differentiation in the lamina propria by inducing serum amyloid A (SAA) production by IECs $[31,32]$. In addition, SFB facilitates type3 innate lymphoid cells (ILC3) to produce Interleukin (IL)-22 in an IL-23 receptor-dependent manner. In the case of Citrobacter rodentium infection associated with enteritis, a potent Th17 cell-mediated response is induced [32]. IL-17 and IL-22 produced by Th17 cells or ILC3 upregulate the secretion of AMPs and Reg3 family proteins by IECs, and induce the fucosylation of cell membrane proteins on IECs of the small intestine, which work to regulate commensal and pathogenic bacteria [20, 33]. When parasite infection occurs, tuft cells, taste-chemosensory epithelial cells, produce IL-25 which activates ILC2 to secrete IL-13. This induces Th2 responses, resulting in an enhancement of mucin production and goblet cell differentiation [34-36].

In mucosal injury, IL-6 derived from intraepithelial lymphocytes enhances intestinal epithelial cell proliferation and contributes to healing from mucosal injury [37]. Moreover, activated macrophages differentiated from monocytes recruited to the mucosal wound site trigger the colonic epithelial progenitor niche with direct cell-cell contact to promote epithelial regeneration, which helps to recover the mucosal barrier [38]. Th2 cytokines, such as IL-5 and IL-13, promote colonic wound healing by inducing the alternative activation of macrophages, which contributes to epithelial cell proliferation [39]. Conversely, other pro-inflammatory cytokines, such as tumor necrosis factor (TNF)- $\alpha$ and interferon (IFN)- $\gamma$, inhibit epithelial cell proliferation through the suppression of $\beta$-catenin/T cell factor signaling [40]. Mucosal barrier function of IECs are maintained by intestinal microbiota and immune cell-derived cytokines (Fig. 2).

\section{Intestinal inflammation induced by the dysfunction of mucosal barriers}

IBD is a group of chronic inflammatory states of the digestive tract, characterized by CD and UC. The incidence and prevalence of IBD are increasing around the world, suggesting that the elucidation of the pathogenesis of IBD is an emergent matter to be solved [41]. Recent remarkable advances of sequencing technology make it possible to identify various IBD susceptibility genes and the gut microbial composition of IBD patients. Accumulated evidence strongly indicates that both gut environmental factors including gut microbiota and host immune dysregulation associated with a genetic predisposition contribute to the occurrence and development of IBD [42]. IECs, which are present between gut microbiota and the host immunity, play an important role in the segregation of both factors by generating mucosal barriers to avoid excessive immune response to gut microbiota, which results in intestinal inflammation. Indeed, GWAS using next generation sequencing technology identified various IBD susceptibility genes including the mucosal barrier-related genes FUT2, MUC19 and NOD2 [43-46]. Additionally, the decreased production of mucosal barrier-related molecules, such as AMPs and mucins, is observed in the intestines of IBD patients [4].

To investigate the roles of mucosal barriers in preventing intestinal inflammation, many studies using genetically modified mice with mucosal barrier impairment have been conducted. Mice devoid of Muc2 show the disappearance of the inner mucus layer and develop spontaneous colitis resulting from the bacterial invasion of the colonic mucosa $[15,47]$. The deficiency of cooperation of core 1 synthase (C1galt), which synthesizes the major constituent of the $O$-glycan core structure of the MUC2 protein, conduces to the disrupted mucus constitution and allows bacteria to invade the inner mucus layer, resulting in spontaneous colitis [19]. Abrogation of IEC fucosylation is associated with intestinal dysbiosis and leads to high susceptibility to intestinal inflammation. $[48,49]$ In mice deficient in Lypd8, a highly $\mathrm{N}$ glycosylated protein expressed on IECs, the invasion of the colonic mucosa by a large number of flagellated bacteria such as Proteus spp. and Escherichia spp. causes high susceptibility to dextran sulfate sodium (DSS)-induced intestinal inflammation [18]. The absence of NLRP6 in IECs impairs mucus secretion from goblet cells, consequently leading to the disappearance of the bacteria-free zone just above the colonic epithelia. This is accompanied with high sensitivity to DSS-induced or bacterial pathogen-induced colitis $[27,50]$. Interestingly, wild-type mice cohoused with NLRP6-deficient mice show high susceptibility to DSS-induced intestinal inflammation, indicating colitogenic dysbiosis of NLRP6deficient mice is transmissible to normal mice [50]. The dysfunction of cell junctions also causes intestinal inflammation. Intestinal deletion of Claudin-7, which is a critical component of the tight junctions of IECs, enhances the paracellular flux of a bacterial product and consequently causes spontaneous colitis in mice [23]. In 


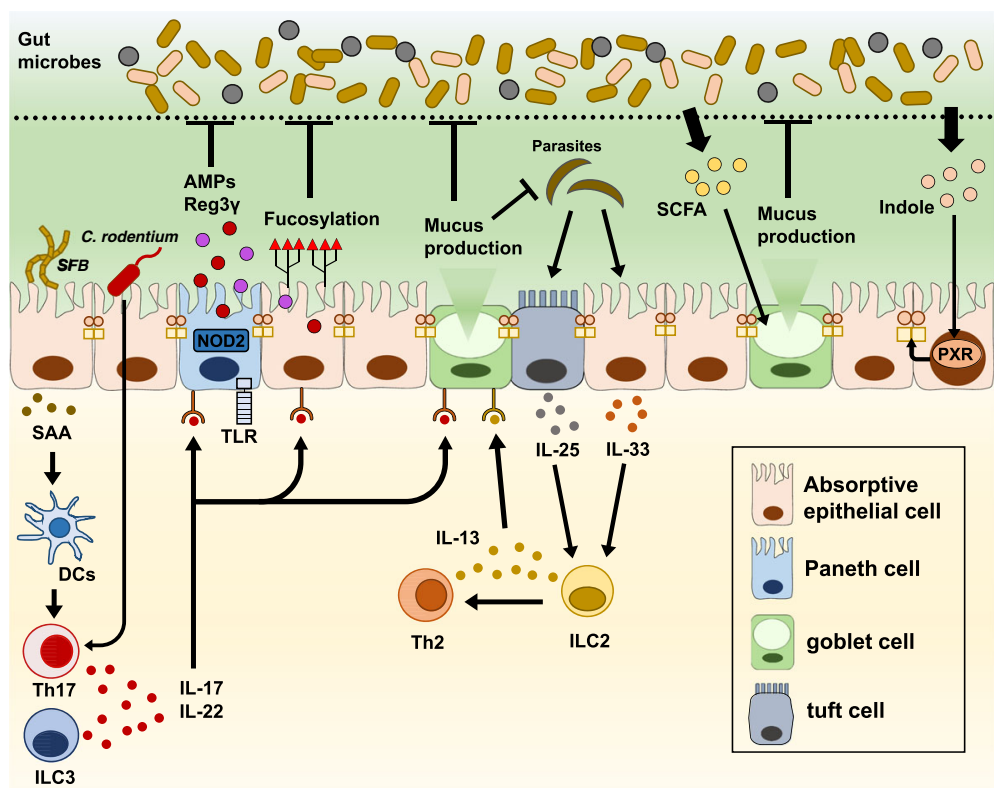

Fig. 2 Regulation of mucosal barrier functions by gut microbes and host immune cells. Mucosal barrier function is modulated by gut microbes and host immune cells. SFB colonization or C. rodentium infection promotes the induction of helper T cells producing IL-17 and simulates ILC3 to secrete IL-22. Both cytokines enhance the production of antimicrobials such as AMPs and Reg3y from IECs. In the case of parasite infection, activated tuft cells produce IL-25, which stimulates ILC2 to secrete IL-13. IL-13 promotes the proliferation of goblet cells and mucus production from them. Metabolites from gut microbes also directly influence the mucosal barrier function of IECs. SCFA promotes mucus production from goblet cells, and indole upregulates the expression of cell junction-related molecules through PXR activationSFB: segmented filamentous bacteria, SAA: serum amyloid A, ILC: innate lymphoid cell, TLR: Toll-like receptor, NOD2: nucleotide-binding oligomerization domain-containing 2, AMP: antimicrobial peptide, IEC: intestinal epithelial cell, SCFA: short-chain fatty acid, PXR: Pregnane X receptor.

addition, in the absence of RING finger protein (RNF) 186, which acts as an E3 ligase to mediate polyubiquitination of its substrates, the sensitivity to intestinal inflammation is elevated because of the high permeability of small organic molecule and enhanced endoplasmic reticulum (ER) stress in IECs [51].

The impairment of chemical barriers also causes high susceptibility to intestinal inflammation. Mice devoid of IL-22 which enhances the production of antimicrobials by IECs also show high sensitivity to DSS colitis, indicating IL-22 from $T$ cells is protective against intestinal inflammation [52]. Moreover, intestinal epithelial cellspecific inhibition of nuclear factor (NF)- $\mathrm{kB}$ through the conditional ablation of NEMO, an I $\mathrm{KB}$ kinase subunit essential for NF- $\mathrm{kB}$ activation, causes chronic intestinal inflammation in mice because of bacterial translocation into the colonic mucosa due to the reduced production of antimicrobial peptides [53]. Mice deficient in the Nod2 gene, which is a susceptibility gene for human CD, do not show spontaneous intestinal inflammation but show severe Th1-driven granulomatous inflammation of the ileum induced by Helicobacter hepaticus because of the decreased expression of AMPs by Paneth cells [54-56]. The deficiency of multi-drug resistance protein 1 (MDR1), a xenobiotic transporter, leads to chronic colitis because of the increased permeability of IECs [57]. Deficiency in adaptor protein (AP)-1B, which mediates the sorting of membrane proteins, induced the reduced expression of antimicrobial proteins and the impaired secretion of IgA, leading to chronic colitis with an enhanced Th17 response [58].

As described above, many human and mouse studies have demonstrated that intestinal barrier dysfunction is clearly implicated in the development of intestinal inflammation, indicating that the segregation of gut microbiota and host immunity by the mucosal barriers is critically involved in maintaining gut homeostasis (Fig. 3).

\section{Conclusions}

IECs generate various kinds of mucosal barriers to segregate gut microbiota and gut immune cells to prevent excessive immune responses leading to intestinal inflammation. Accordingly, a defect in mucosal barrier function promotes the development of intestinal inflammation such as IBD. There are three major players involved in the pathogenesis of IBD. These include gut microbes in the lumen, immune cells in the lamina propria and IECs between the two. Regarding therapies for IBD, there are several immunosuppressive agents such as mesalazine, steroids and infliximab. Recently, fecal transplantation has been developed to 

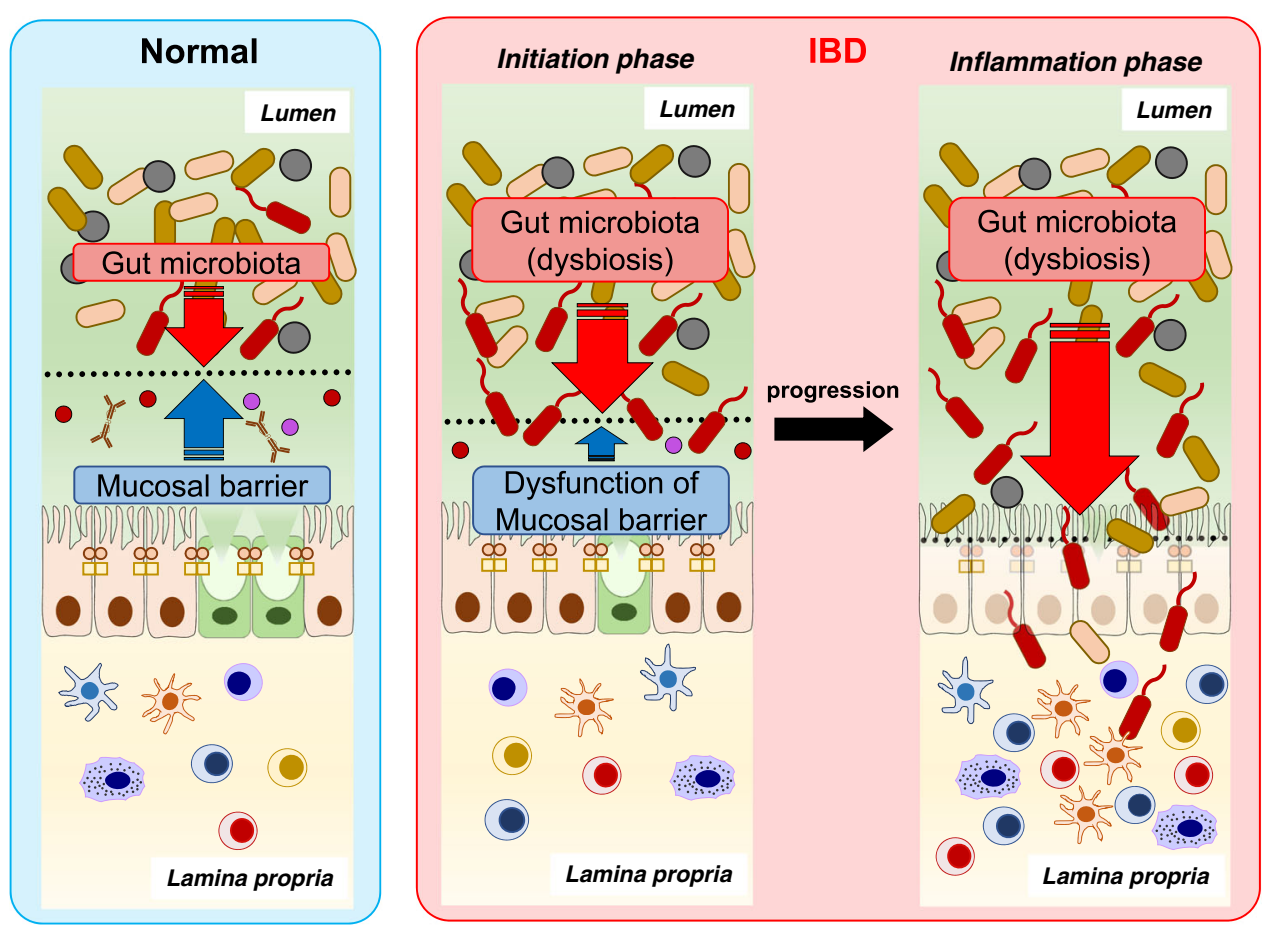

Fig. 3 The imbalance between mucosal barriers and gut microbes promotes susceptibility to intestinal inflammation. In the steady state, intestinal bacteria and mucosal barriers maintain a well-balanced relationship, and thus intestinal bacteria and IECs are clearly segregated in the gut. However, dysfunction of mucosal barriers including decreased production of mucin or AMPs due to genetic factors and dysbiosis induced by environmental factors such as high-fat diet or various antibiotics disrupt the well-balanced relationship, and thereby intestinal bacteria can gain access to the gut immune cells, leading to the progression of IBD. IBD: inflammatory bowel disease

improve the gut environment. However, extremely few therapies targeting the mucosal barrier function of IECs exist. The therapies for intractable IBD are limited, and several different immunosuppressive therapies are required, each having at least a few side effects. Further clarification of the mechanisms regulating the gut mucosal barrier system will certainly shed light on the development of novel therapeutic approaches for IBD.

\section{Abbreviations}

AMP: Antimicrobial peptide; AP: Adaptor protein; C1galt: Cooperation of core 1 synthase; CD: Crohn's disease; DSS: Dextran sulfate sodium; ER: Endoplasmic reticulum; GWAS: Genome-wide association study; IBD: Inflammatory bowel disease; IEC: Intestinal epithelial cell; IFN: Interferon; IgA: Immunoglobulin A; IL: Interleukin; ILC: Innate lymphoid cell; Lypd8: Ly6/Plaur domain containing 8; MDR: Multi-drug resistance protein; MMP-7: Matrix metalloproteinase-7; NEMO: Inhibitor of nuclear factor kappa B kinase subunit gamma; NF: Nuclear factor; NLRP6: NOD-like receptor family pyrin domain containing 6; NOD2: Nucleotide-binding oligomerization domain-containing protein 2 PXR: Pregnane X receptor; Reg3: Regenerating islet-derived 3; RNF: RING finger protein; SAA: Serum amyloid A; SCFA: Short-chain fatty acid; SFB: Segmented filamentous bacteria; TLR: Toll-like receptor; TNF: Tumor necrosis factor; $T_{\text {reg: }}$ : Regulatory $T$ cell; UC: Ulcerative colitis

\section{Acknowledgements}

We thank T. Kondo, and Y. Magota for their technical assistance, and C. Hidaka for secretarial assistance.

\section{Funding}

Not applicable.
Availability of data and materials Not applicable.

\section{Authors' contributions}

$\mathrm{RO}$. drafted the original manuscript. $K T$. revised the manuscript and gave final approval of the version to be published. All authors read and approved the manuscript.

Ethics approval and consent to participate

Not applicable.

\section{Consent for publication}

Not applicable.

\section{Competing interests}

The authors declare that they have no competing financial interests.

\section{Publisher's Note}

Springer Nature remains neutral with regard to jurisdictional claims in published maps and institutional affiliations.

\section{Author details}

'Department of Microbiology and Immunology, Graduate School of Medicine, Osaka University, Osaka 565-0871, Japan. ${ }^{2}$ WPI Immunology Frontier Research Center, Osaka University, Osaka 565-0871, Japan. ${ }^{3}$ Core Research for Evolutional Science and Technology, Japan Agency for Medical Research and Development, Tokyo 100-0004, Japan. 


\section{Received: 31 January 2018 Accepted: 4 March 2018}

\section{Published online: 02 April 2018}

\section{References}

1. Gaudier E, Jarry A, Blottiere HM, de Coppet P, Buisine MP, Aubert JP, Laboisse C, Cherbut C, Hoebler C. Butyrate specifically modulates MUC gene expression in intestinal epithelial goblet cells deprived of glucose. Am J Physiol Gastrointest Liver Physiol. 2004;287(6):G1168-74.

2. Furusawa $Y$, Obata $Y$, Fukuda S, Endo TA, Nakato G, Takahashi D, Nakanishi Y, Uetake C, Kato K, Kato T, et al. Commensal microbe-derived butyrate induces the differentiation of colonic regulatory T cells. Nature. 2013; 504(7480):446-50.

3. Shimotoyodome A, Meguro S, Hase T, Tokimitsu I, Sakata T. Short chain fatty acids but not lactate or succinate stimulate mucus release in the rat colon. Comp Biochem Physiol A Mol Integr Physiol. 2000;125(4):525-31.

4. Jager S, Stange EF, Wehkamp J. Inflammatory bowel disease: an impaired barrier disease. Langenbeck's Arch Surg. 2013;398(1):1-12.

5. Ayabe T, Satchell DP, Wilson CL, Parks WC, Selsted ME, Ouellette AJ. Secretion of microbicidal alpha-defensins by intestinal Paneth cells in response to bacteria. Nat Immunol. 2000;1(2):113-8.

6. Vaishnava S, Yamamoto M, Severson KM, Ruhn KA, Yu X, Koren O, Ley R, Wakeland EK, Hooper LV. The antibacterial lectin Reglllgamma promotes the spatial segregation of microbiota and host in the intestine. Science. 2011; 334(6053):255-8.

7. Salzman NH, Underwood MA, Bevins CL. Paneth cells, defensins, and the commensal microbiota: a hypothesis on intimate interplay at the intestinal mucosa. Semin Immunol. 2007;19(2):70-83.

8. Brogden KA. Antimicrobial peptides: pore formers or metabolic inhibitors in bacteria? Nat Rev Microbiol. 2005;3(3):238-50.

9. Wilson CL, Ouellette AJ, Satchell DP, Ayabe T, Lopez-Boado YS, Stratman JL, Hultgren SJ, Matrisian LM, Parks WC. Regulation of intestinal alpha-defensin activation by the metalloproteinase matrilysin in innate host defense. Science. 1999;286(5437):113-7.

10. Salzman NH, Hung K, Haribhai D, Chu H, Karlsson-Sjoberg J, Amir E, Teggatz P, Barman M, Hayward M, Eastwood D, et al. Enteric defensins are essential regulators of intestinal microbial ecology. Nat Immunol. 2010;11(1):76-83.

11. Salzman NH, Bevins CL. Dysbiosis-a consequence of Paneth cell dysfunction. Semin Immunol. 2013;25(5):334-41.

12. Mukherjee $\mathrm{S}$, Zheng $\mathrm{H}$, Derebe $\mathrm{MG}$, Callenberg KM, Partch $\mathrm{CL}$, Rollins $\mathrm{D}$, Propheter DC, Rizo J, Grabe M, Jiang QX, et al. Antibacterial membrane attack by a pore-forming intestinal C-type lectin. Nature. 2014;505(7481):103-7.

13. Cash HL, Whitham CV, Behrendt CL, Hooper LV. Symbiotic bacteria direct expression of an intestinal bactericidal lectin. Science. 2006;313(5790):1126-30.

14. Rodriguez-Pineiro AM, Bergstrom JH, Ermund A, Gustafsson JK, Schutte A, Johansson ME, Hansson GC. Studies of mucus in mouse stomach, small intestine, and colon. II. Gastrointestinal mucus proteome reveals Muc2 and Muc5ac accompanied by a set of core proteins. Am J Physiol Gastrointest Liver Physiol. 2013;305(5):G348-56.

15. Johansson ME, Phillipson M, Petersson J, Velcich A, Holm L, Hansson GC The inner of the two Muc2 mucin-dependent mucus layers in colon is devoid of bacteria. Proc Natl Acad Sci U S A. 2008;105(39):15064-9.

16. Desai MS, Seekatz AM, Koropatkin NM, Kamada N, Hickey CA, Wolter M, Pudlo NA, Kitamoto S, Terrapon N, Muller A, et al. A dietary Fiber-deprived gut microbiota degrades the colonic mucus barrier and enhances pathogen susceptibility. Cell. 2016;167(5):1339-53. e1321

17. Maynard CL, Elson CO, Hatton RD, Weaver CT. Reciprocal interactions of the intestinal microbiota and immune system. Nature. 2012;489(7415):231-41.

18. Okumura R, Kurakawa T, Nakano T, Kayama H, Kinoshita M, Motooka D, Gotoh K, Kimura T, Kamiyama N, Kusu T, et al. Lypd8 promotes the segregation of flagellated microbiota and colonic epithelia. Nature. 2016; 532(7597):117-21.

19. Fu J, Wei B, Wen T, Johansson ME, Liu X, Bradford E, Thomsson KA, McGee $\mathrm{S}$, Mansour L, Tong M, et al. Loss of intestinal core 1-derived O-glycans causes spontaneous colitis in mice. J Clin Invest. 2011;121(4):1657-66.

20. Goto Y, Obata T, Kunisawa J, Sato S, Ivanov II, Lamichhane A, Takeyama N, Kamioka M, Sakamoto M, Matsuki T, et al. Innate lymphoid cells regulate intestinal epithelial cell glycosylation. Science. 2014;345(6202):1254009.

21. Pham TA, Clare S, Goulding D, Arasteh JM, Stares MD, Browne HP, Keane JA Page AJ, Kumasaka N, Kane L, et al. Epithelial IL-22RA1-mediated fucosylation promotes intestinal colonization resistance to an opportunistic pathogen. Cell Host Microbe. 2014;16(4):504-16.
22. Nagpal R, Yadav H. Bacterial translocation from the gut to the distant organs: an overview. Ann Nutr Metab. 2017;71(Suppl 1):11-6.

23. Tanaka H, Takechi M, Kiyonari H, Shioi G, Tamura A, Tsukita S. Intestinal deletion of Claudin-7 enhances paracellular organic solute flux and initiates colonic inflammation in mice. Gut. 2015;64(10):1529-38.

24. Kobayashi KS, Chamaillard M, Ogura Y, Henegariu O, Inohara N, Nunez G, Flavell RA. Nod2-dependent regulation of innate and adaptive immunity in the intestinal tract. Science. 2005;307(5710):731-4.

25. Frantz AL, Rogier EW, Weber CR, Shen L, Cohen DA, Fenton LA, Bruno ME, Kaetzel CS. Targeted deletion of MyD88 in intestinal epithelial cells results in compromised antibacterial immunity associated with downregulation of polymeric immunoglobulin receptor, mucin-2, and antibacterial peptides. Mucosal Immunol. 2012:5(5):501-12.

26. Bhinder G, Stahl M, Sham HP, Crowley SM, Morampudi V, Dalwadi U, Ma C, Jacobson K, Vallance BA. Intestinal epithelium-specific MyD88 signaling impacts host susceptibility to infectious colitis by promoting protective goblet cell and antimicrobial responses. Infect Immun. 2014;82(9):3753-63.

27. Wlodarska M, Thaiss CA, Nowarski R, Henao-Mejia J, Zhang JP, Brown EM, Frankel G, Levy M, Katz MN, Philbrick WM, et al. NLRP6 inflammasome orchestrates the colonic host-microbial interface by regulating goblet cell mucus secretion. Cell. 2014:156(5):1045-59.

28. Burger-van Paassen N, Vincent A, Puiman PJ, van der Sluis M, Bouma J, Boehm G, van Goudoever JB, van Seuningen I, Renes IB. The regulation of intestinal mucin MUC2 expression by short-chain fatty acids: implications for epithelial protection. Biochem J. 2009;420(2):211-9.

29. Shimada Y, Kinoshita M, Harada K, Mizutani M, Masahata K, Kayama H, Takeda K. Commensal bacteria-dependent indole production enhances epithelial barrier function in the colon. PLoS One. 2013; 8(11):e80604

30. Venkatesh M, Mukherjee S, Wang H, Li H, Sun K, Benechet AP, Qiu Z, Maher L, Redinbo MR, Phillips RS, et al. Symbiotic bacterial metabolites regulate gastrointestinal barrier function via the xenobiotic sensor PXR and toll-like receptor 4. Immunity. 2014;41(2):296-310.

31. Ivanov II, Atarashi K, Manel N, Brodie EL, Shima T, Karaoz U, Wei D, Goldfarb KC, Santee CA, Lynch SV, et al. Induction of intestinal Th17 cells by segmented filamentous bacteria. Cell. 2009;139(3):485-98.

32. Atarashi K, Tanoue T, Ando M, Kamada N, Nagano Y, Narushima S, Suda W, Imaoka A, Setoyama H, Nagamori T, et al. Th17 cell induction by adhesion of microbes to intestinal epithelial cells. Cell. 2015;163(2):367-80.

33. Liang SC, Tan XY, Luxenberg DP, Karim R, Dunussi-Joannopoulos $K$, Collins M, Fouser LA. Interleukin (IL)-22 and IL-17 are coexpressed by Th17 cells and cooperatively enhance expression of antimicrobial peptides. J Exp Med. 2006;203(10):2271-9.

34. Gerbe F, Sidot E, Smyth DJ, Ohmoto M, Matsumoto I, Dardalhon V, Cesses P, Garnier L, Pouzolles M, Brulin B, et al. Intestinal epithelial tuft cells initiate type 2 mucosal immunity to helminth parasites. Nature. 2016;529(7585):226-30.

35. Howitt MR, Lavoie S, Michaud M, Blum AM, Tran SV, Weinstock JV, Gallini CA, Redding K, Margolskee RF, Osborne LC, et al. Tuft cells, tastechemosensory cells, orchestrate parasite type 2 immunity in the gut. Science. 2016;351(6279):1329-33.

36. von Moltke J, Ji M, Liang HE, Locksley RM. Tuft-cell-derived IL-25 regulates an intestinal ILC2-epithelial response circuit. Nature. 2016;529(7585):221-5.

37. Kuhn KA, Manieri NA, Liu TC, Stappenbeck TS. IL-6 stimulates intestinal epithelial proliferation and repair after injury. PLoS One. 2014;9(12):e114195.

38. Pull SL, Doherty JM, Mills JC, Gordon JI, Stappenbeck TS. Activated macrophages are an adaptive element of the colonic epithelial progenitor niche necessary for regenerative responses to injury. Proc Natl Acad Sci U S A. 2005:102(1):99-104

39. Seno H, Miyoshi H, Brown SL, Geske MJ, Colonna M, Stappenbeck TS. Efficient colonic mucosal wound repair requires Trem2 signaling. Proc Natl Acad Sci U S A. 2009;106(1):256-61.

40. Capaldo CT, Beeman N, Hilgarth RS, Nava P, Louis NA, Naschberger E, Sturzl M, Parkos CA, Nusrat A. IFN-gamma and TNF-alpha-induced GBP1 inhibits epithelial cell proliferation through suppression of betacatenin/TCF signaling. Mucosal Immunol. 2012;5(6):681-90

41. Molodecky NA, Soon IS, Rabi DM, Ghali WA, Ferris M, Chernoff G, Benchimol El, Panaccione R, Ghosh S, Barkema HW, et al. Increasing incidence and prevalence of the inflammatory bowel diseases with time, based on systematic review. Gastroenterology. 2012;142(1):46-54. e42; quiz e30

42. Goto $Y$, Kurashima $Y$, Kiyono $H$. The gut microbiota and inflammatory bowel disease. Curr Opin Rheumatol. 2015;27(4):388-96. 
43. Anderson CA, Boucher G, Lees CW, Franke A, D'Amato M, Taylor KD, Lee JC, Goyette P, Imielinski M, Latiano A, et al. Meta-analysis identifies 29 additional ulcerative colitis risk loci, increasing the number of confirmed associations to 47. Nat Genet. 2011;43(3):246-52.

44. Franke A, McGovern DP, Barrett JC, Wang K, Radford-Smith GL, Ahmad T, Lees CW, Balschun T, Lee J, Roberts R, et al. Genome-wide meta-analysis increases to 71 the number of confirmed Crohn's disease susceptibility loci. Nat Genet. 2010;42(12):1118-25.

45. Jostins L, Ripke S, Weersma RK, Duerr RH, McGovern DP, Hui KY, Lee JC, Schumm LP, Sharma Y, Anderson CA, et al. Host-microbe interactions have shaped the genetic architecture of inflammatory bowel disease. Nature. 2012;491 (7422):119-24

46. Liu JZ, van Sommeren S, Huang H, Ng SC, Alberts R, Takahashi A, Ripke S, Lee JC, Jostins L, Shah T, et al. Association analyses identify 38 susceptibility loci for inflammatory bowel disease and highlight shared genetic risk across populations. Nat Genet. 2015;47(9):979-86.

47. Van der Sluis M, De Koning BA, De Bruijn AC, Velcich A, Meijerink JP, Van Goudoever JB, Buller HA, Dekker J, Van Seuningen I, Renes IB, et al. Muc2deficient mice spontaneously develop colitis, indicating that MUC2 is critical for colonic protection. Gastroenterology. 2006;131(1):117-29.

48. Pickard JM, Maurice CF, Kinnebrew MA, Abt MC, Schenten D, Golovkina TV Bogatyrev SR, Ismagilov RF, Pamer EG, Turnbaugh PJ, et al. Rapid fucosylation of intestinal epithelium sustains host-commensal symbiosis in sickness. Nature. 2014;514(7524):638-41.

49. Wang Y, Huang $D$, Chen KY, Cui M, Wang W, Huang X, Awadellah A, Li Q, Friedman A, Xin WW, et al. Fucosylation deficiency in mice leads to colitis and adenocarcinoma. Gastroenterology. 2017;152(1):193-205.

50. Elinav E, Strowig T, Kau AL, Henao-Mejia J, Thaiss CA, Booth CJ, Peaper DR Bertin J, Eisenbarth SC, Gordon JI, et al. NLRP6 inflammasome regulates colonic microbial ecology and risk for colitis. Cell. 2011;145(5):745-57.

51. Fujimoto K, Kinoshita M, Tanaka H, Okuzaki D, Shimada Y, Kayama H, Okumura R, Furuta Y, Narazaki M, Tamura A, et al. Regulation of intestinal homeostasis by the ulcerative colitis-associated gene RNF186. Mucosal Immunol. 2017;10(2):446-59.

52. Zenewicz LA, Yancopoulos GD, Valenzuela DM, Murphy AJ, Stevens S, Flavell RA. Innate and adaptive interleukin-22 protects mice from inflammatory bowel disease. Immunity. 2008;29(6):947-57.

53. Nenci A, Becker C, Wullaert A, Gareus R, van Loo G, Danese S, Huth M, Nikolaev A, Neufert C, Madison B, et al. Epithelial NEMO links innate immunity to chronic intestinal inflammation. Nature. 2007;446(7135):557-61.

54. Hugot JP, Chamaillard M, Zouali H, Lesage S, Cezard JP, Belaiche J, Almer S, Tysk C, O'Morain CA, Gassull M, et al. Association of NOD2 leucine-rich repeat variants with susceptibility to Crohn's disease. Nature. 2001;411(6837):599-603.

55. Biswas A, Liu YJ, Hao L, Mizoguchi A, Salzman NH, Bevins CL, Kobayashi KS. Induction and rescue of Nod2-dependent Th1-driven granulomatous inflammation of the ileum. Proc Natl Acad Sci U S A. 2010;107(33):14739-44.

56. Ogura Y, Bonen DK, Inohara N, Nicolae DL, Chen FF, Ramos R, Britton H, Moran $\mathrm{T}$, Karaliuskas R, Duerr RH, et al. A frameshift mutation in NOD2 associated with susceptibility to Crohn's disease. Nature. 2001;411(6837):603-6.

57. Resta-Lenert S, Smitham J, Barrett KE. Epithelial dysfunction associated with the development of colitis in conventionally housed mdr1a-/- mice. Am J Physiol Gastrointest Liver Physiol. 2005;289(1):G153-62.

58. Takahashi D, Hase K, Kimura S, Nakatsu F, Ohmae M, Mandai Y, Sato T, Date Y, Ebisawa M, Kato T, et al. The epithelia-specific membrane trafficking factor AP-1B controls gut immune homeostasis in mice. Gastroenterology. 2011;141(2):621-32.

\section{Submit your next manuscript to BioMed Central and we will help you at every step:}

- We accept pre-submission inquiries

- Our selector tool helps you to find the most relevant journal

- We provide round the clock customer support

- Convenient online submission

- Thorough peer review

- Inclusion in PubMed and all major indexing services

- Maximum visibility for your research

Submit your manuscript at www.biomedcentral.com/submit
) Biomed Central 